\title{
An Empirical Study of the Effectiveness of Negotiation of Meaning in L2 Vocabulary Acquisition of Chinese Learners of English
}

\author{
Baoshu Yi ${ }^{1} \&$ Zhinong Sun $^{1}$ \\ ${ }^{1}$ School of Foreign Languages, Anhui Agricultural University, China \\ Correspondence: Baoshu Yi, School of Foreign Languages, Anhui Agricultural University, 130 Chang Jiang \\ Western Road, Hefei City, Anhui, 230036, China. E-mail: yibaoshu111@163.com
}

Received: June 7, 2013 Accepted: July 18, 2013 Online Published: September 4, 2013

doi:10.5539/elt.v6n10p120 URL: http://dx.doi.org/10.5539/elt.v6n10p120

\begin{abstract}
The study aimed to investigate whether or not negotiation of meaning is effective in L2 vocabulary acquisition of Chinese learners of English in the classroom setting. In the study there were two experimental groups (pre-modified input and negotiation of meaning) and two control groups (pre-modified input). The four groups were required to do a pre-vocabulary test, a match task and a post-vocabulary test respectively. The study showed: (1) as far as the high school groups are concerned, the experimental group outperformed the control group in terms of comprehensible input in the match task. The experimental group also did better than the control group in terms of acquiring new words in the post-vocabulary test. A strong correlation is found between comprehensible input, negotiation of meaning and acquiring new words in the high school groups; 2) As regards the college groups, the experimental group also outperformed the control group in terms of acquiring new words in the post-vocabulary test; however, two groups had no difference in obtaining comprehensible input in the match task, and no correlation was found between comprehensible input, negotiation of meaning and acquiring new words.
\end{abstract}

Keywords: negotiation of meaning, comprehensible input, L2 vocabulary acquisition

\section{Introduction}

The contribution of classroom interaction to the language development has indeed been the focus for a considerable amount of work over the last few decades (Breen, 2002; Bitchener, 2003; Foster, 1998; Fuente, 2002, 2006; Hardy \& Moore, 2004; Krashen, 1980, 1985; Long, 1981; 1996; Pica, 1991, 1994; Swain, 1985; Zhao \&Bitchener, 2007; Gass \& Torres, 2005; Long, 2011; Luan \& Sappathy, 2011). Recently, many researchers have studied the role of negotiation of meaning in second language acquisition (Foster\& Ohta, 2005; Gass \& Vanoris, 1985, 1994; Lee, 2005; Lee, 2006; Long, 1983, 1996; 2011; Luan\& Sappathy, 2011; Pica, 1987, 1994, Révész, et al, 2011; Yong, 1983). In the field of the foreign language classroom setting, especially in China, however, less attention is paid to the role of negotiation of meaning. Therefore, this paper intends to fill the gap by examining the effectiveness of negotiation of meaning in L2 vocabulary acquisition of Chinese learners of English in the classroom setting.

\section{Literature Review}

\subsection{Negotiation of Meaning}

Negotiation of meaning refers to interactional work done by interlocutors to achieve mutual understanding when a communication problem occurs. Pica (1994) explored a specific type of interaction known as negotiation of meaning which has been used to characterize modification and restructuring of interaction that occurs when learners and their interlocutors perceive difficulties in message comprehensibility. Negotiation sequences have been identified by Ellis (2005) as clarification requests, confirmation checks, recasts, etc. Long (1985) regarded them as types of interactional modification. Whatever labels are used, these features of negotiation portray a process in which a listener requests message clarification and confirmation, and the speaker follows up these requests through repeating, elaborating or simplifying the original message. Recent studies support the position that interaction embodied into meaning of negotiation helps learners to comprehend non-understanding when a problem occurs so that comprehension ultimately contributes to successful SLA (Jeong, 2011). The interaction hypothesis developed by Long (1985) shows how negotiation of meaning raises L2 acquisition (Ellis, 2003). 


\subsection{Negotiation of Meaning and the Interaction Hypothesis}

According to Long (1985), in an NNS-NS (a non-native speaker and a native speaker) encounter, both parties would experience difficulty in comprehension and expression, and they would therefore modify interaction, in particular, the NS would modify the speech to such a level that is appropriate to the NNS. The modification has two results: Firstly, it keeps interaction going and gets things done; Secondly, it provides comprehensible input. The more L2 interaction the learner holds with others, the more negotiation of meaning would take place, and subsequently, the more comprehensible input the learner would receive.

In other words, when a learner interacts with someone who might be another learner or a teacher, the learner receives input and produces output. Because learners do not know the language perfectly, it is natural that their attempts to interact should sometimes go wrong and misunderstandings may occur. When this happens, it is known as negotiation of meaning defined by Ellis as interactive work that takes place between the speakers when some misunderstandings occur (Ellis, 1997: 141). This may involve saying things again, using other words or simpler structures, and a number of gestures, etc. Through negotiation of meaning, learners try out their own language by making their own choices and errors when using the target language in communicative contexts, which play a vital role in learners' linguistic development.

To sum up, negotiation of meaning can occur during normal communications between proficient speakers and less proficient speakers. Both proficient and less proficient speakers are believed to benefit from negotiation of meaning. All in all, the interaction hypothesis claims that it is in the interaction process that acquisition may occur effectively. Learners acquire target language through talking with native speakers, teachers, or other interlocutors.

\subsection{Negotiation of Meaning and Vocabulary Acquisition}

The lexicon of a language is central to language acquisition as it provides a unique window on the process of acquisition for language as a whole. Currently, the issue of vocabulary acquisition has drawn more and more attention in second language pedagogy and research. In particular, the role of negotiation of meaning in L2 vocabulary acquisition is drawing the attention of many researchers (Pica, 1993, 1994; Long, 1996; Ellis, 1985, 1995, Loschky, 1994; Fuente, 2002, 2006; Blake, 2000; Luan \& Sappathy, 2011; Bitchener, 2003; Ellis \& He, 1999; Ellis \& Heimbach, 1997; Ellis, et al., 1994).

Pica (1993, 1994) claims that negotiation of meaning is far more likely to concern lexical items than grammatical morphology and that negotiated interaction may be beneficial for lexical learning.

Long (1996) states that negative feedback obtained in negotiation work or elsewhere may be of great use in L2 development and it is also good for vocabulary learning. This indirect evidence indicates that negotiation of meaning could play an important role in second language vocabulary acquisition.

There are some empirical studies examining the effects of negotiation of meaning on vocabulary comprehension. Ellis (1985) demonstrates that pre-modified input (input that has been simplified and made more redundant) is actually more efficient than interactional modified input (the subjects listen to unmodified instructions but are given the opportunity to seek clarification) in terms of the number of new words acquired per minute on task. However, later, Ellis et al (1994) re-establishes that negotiation of meaning results in a better comprehension and receptive acquisition of vocabulary than pre-modified input, providing evidence for a link between modified input through negotiation of meaning and vocabulary acquisition.

In a study carried out by Zhao \& Bitchener (2007), it is found that negotiation of meaning occurs in interaction when dealing with linguistic difficulties. However, in the learner-learner interactions, there is more questioning which enables learners to initiate opportunities for accessing target language data for the immediate resolution of language difficulties (Zhao \& Bitchener, 2007: 446) which predicts their L2 learning and vocabulary acquisition.

A recent study by Luan \& Sappathy (2011) examines the relationship between negotiated interaction and the ability to retain vocabulary items among a group of primary school learners with similar first languages. The results show that learners who negotiate for meaning in the two-way task achieve higher vocabulary test scores. The 24 students involved in the interactive task demonstrate their ability to negotiate for meaning despite their lack of proficiency in the language. As negotiated interaction has proved successful in enabling students to acquire and retain vocabulary items, such interactive tasks should be encouraged in the classroom.

From the above literature, it seems that comprehension promotes language acquisition and negotiation of meaning leads to better comprehension. It also implies that negotiation of meaning contributes to language acquisition. Negotiation of meaning is believed to aid L2 vocabulary acquisition. 
However, as regards negotiation of meaning, some criticisms remain: Contrary to many relevant studies, Foster (1998) holds that negotiation of meaning is not a strategy that language learners are predisposed to employ when they encounter gaps in their understanding. There is little evidence of negotiation in her data, suggesting that there is a difference between laboratory and classroom settings with regard to the amount of negotiation produced. Because of the small amount of negotiation in any of her tasks, she concludes that un-coached negotiation for meaning does not occur in the classroom. The classroom is not a fertile context for negotiation of meaning to take place because teachers consider this type of interaction to be inefficient in their lessons.

In view of the above, the study aims to examine the effectiveness of negotiation of meaning on vocabulary acquisition in the classroom setting by examining the following two questions.

1) When learning new words, can learners with negotiation of meaning acquire more comprehensible input than those without negotiation of meaning?

2) Is there a positive correlation between negotiation of meaning and L2 vocabulary acquisition in the classroom setting?

\section{Methodology}

\subsection{Subjects}

In total, one hundred and eighty-two students participated in the study. One hundred students were from the high school and eighty two were from the college. The students in the high school groups shared similar experience in the following factors: 1) They were all in Grade 8, aged from 13 to 15, and they were all from the same district with similar learning experience in English; 2) They were all native Chinese speakers, which meant that Chinese as their mother tongue was predominantly used in daily life. The college participants also shared similar experience in terms of the following factors: 1) They were all freshmen in the college, aged from 18 to $21 ; 2$ ) They were all native Chinese speakers. Speaking Chinese was inevitable while they were learning English.

\subsection{Experimental Groups and Control Groups}

All the subjects were divided into four groups: two experimental groups and two control groups. The detailed information is described in Table 1:

Table 1. Division of groups and their features

\begin{tabular}{ll}
\hline Groups & Features \\
\hline Group 1 (College experimental group) $(\mathrm{n}=42)$ & Pre-modified input + Negotiation of meaning \\
Group 2 (High school experimental group) $(\mathrm{n}=56)$ & Pre-modified input + Negotiation of meaning \\
Group 3 (College control group) $(\mathrm{n}=38)$ & Pre-modified input \\
Group 4 (High school control group) $(\mathrm{n}=42)$ & Pre-modified input \\
\hline
\end{tabular}

Group 1 and Group 2 are experimental groups in which the participants are able to receive pre-modified input (input that has been simplified and made more redundant) and negotiate meaning with their teachers or peers simultaneously. Group 3 and Group 4 are control groups in which the participants can only receive pre-modified input without negotiation of meaning.

\subsection{Transcription}

In this study, all the conversations (teachers and students or students and their peers) during performing the tasks were transcribed. Any unclear sounds were deleted immediately so that only 178 pieces of the recordings were transcribed clearly in the research though there were 182 participants in this experiment. When transcription was done, checking required the same time, effort, and attention as transcribing was done in the first place. Each transcription in this paper was checked by the other researcher who was invited, through which a more plausible and scientific transcription could be obtained.

\subsection{Procedure}

The whole experiment was divided into three phases: pre-task phase, during-task phase and post-task phase. The detailed information is presented in Table 2: 
Table 2. A series of tasks and their purposes

\begin{tabular}{lll}
\hline Phase & Task & Purpose \\
\hline Pre-task & $\begin{array}{l}\text { Pre-vocabulary tests } \\
\text { (Test } 1 \text { and Test 2) }\end{array}$ & $\begin{array}{l}\text { To find the participant's vocabulary level and make } \\
\text { sure what words or phrases are new to them. }\end{array}$ \\
During-task & $\begin{array}{l}\text { Match tasks } \\
\text { (Match task 1 and Match task 2) }\end{array}$ & $\begin{array}{l}\text { To obtain frequency of negotiation of meaning and the } \\
\text { results of comprehensible input }\end{array}$ \\
Post-task & $\begin{array}{l}\text { Post-vocabulary tests } \\
\text { (A week later) }\end{array}$ & $\begin{array}{l}\text { (Test 3 and Test 4) } \\
\text { acquiring new words }\end{array}$ \\
\hline
\end{tabular}

According to Table 2, in the pre-task phase, there were two vocabulary tests (Test 1 and Test 2). In Test 1, the high school participants were requested to translate 30 English words or phrases into Chinese, and then the researcher could find out what words or phrases were new to them. Ten words and phrases were selected: take after, I won't be long, pull down, set up, used to, separate, downtown, be terrified of, block, ocean.

In Test 2, the college participants were also asked to translate 30 English words into Chinese, and the words that were new to the participants were picked out. Five words were selected to be ready for the next test. They were drastic, contraption, reiterate, drudge, contingent.

In the during-task phase, the participants were asked to do the match tasks. Match task 1 consisted of eleven pictures and ten words or phrases. The participants in Group 2 were required to match the pictures and the words according to the researcher's explanation and negotiating meaning with peers or teachers while the participants in Group 4 were required to match the pictures and the words without negotiation of meaning with others. Both of the groups must complete the tasks within 15 minutes.

Match task 2 consisted of five Chinese and five English words. They were selected carefully after Test2. The participants in Group 1 were requested to match Chinese words and English words according to the researcher's English explanation with the help of negotiating meaning with peers or teachers while those in Group 3 were asked to do the same thing without the help of negotiation of meaning.

In the match tasks, if a participant got one match correct, he/she could obtain one point. The total score for Group 2 and Group 4 was 10 points while the total score for Group 1 and Group 3 was 5 points.

In the post-task phase which happened a week later, it included two post-vocabulary tests (Test 3 and Test 4). In Test 3, the high school participants were asked to fill in the blanks with the words given, which the participants in Group 2 and Group 4 had already learnt before. In Test 4, the college participants were requested to fill in the blanks with the right words, which the participants in Group 1 and Group 3 had also learnt before. If a participant got one question right, he or she could obtain one point.

\subsection{Measurement of Frequency of Negotiation of Meaning}

Frequency of negotiation of meaning was calculated when the participants' conversation records were transcribed. Frequency of negotiation of meaning was counted with reference to C-units as well as T-units. In the experiment, ways of negotiation of meaning include repetition, confirmation, confirmation check, clarification request (Vanoris \& Gass, 1985), pretend (Foster 1998), avoidance of the topic, deliberate change of the topic (Lee, 2001), recasting ( Ellis, 2003), and the use of the first language. For instance:

Teacher: separate means divide. Anyone can not separate Taiwan from us (pre-modified input)

Student 1/Student 2: open... it? (Clarification request)

Teacher: similar to open...But not open (recasting)

Student 1/Student 2: similar to open? FenKai? (Confirmation check and the use of L1)

Teacher: That' right. (Confirmation)

In this dialogue, frequency of negotiation of meaning is counted to be 5 (clarification request, recasting, the use of L1, confirmation check and confirmation).

\section{Results and Discussion}

\subsection{Results}

The data collected in this experiment are finally analyzed by SPSS 17 with an aim of showing whether or not 
there are any differences in comprehensible input and vocabulary score between the control groups and the experimental groups in the match tasks and the post-vocabulary tests.

Table 3. The results of independent samples T-test in terms of comprehensible input and vocabulary score

\begin{tabular}{lllllll}
\hline High school & Group & $\mathrm{N}$ & Mean & Std. Deviation & T-value & P-value \\
\hline Comprehensible & Control group & 42 & 5.4048 & 2.16468 & 11.244 & 0.000 \\
& Experimental group & 56 & 9.3750 & 1.31512 & & \\
Vocabulary score & Control group & 42 & 2.1667 & 1.54473 & & \multirow{2}{*}{0.000} \\
& Experimental group & 56 & 5.8393 & 2.22201 & & \\
\hline College school & Group & $\mathrm{N}$ & Mean & Std. Deviation & T-value & P-value \\
\hline Comprehensible & Control group & 38 & 5.0000 & $.00000^{\mathrm{a}}$ & $*$ & $*$ \\
input & Experimental group & 42 & 5.0000 & $.00000^{\mathrm{a}}$ & & \\
Vocabulary score & Control group & 38 & 2.1579 & 1.44309 & & \\
& Experimental group & 42 & 3.7143 & 1.45310 & 4.800 & 0.000 \\
\end{tabular}

* T cannot be computed because the standard deviations of both groups are 0 .

Table 3 shows that in the high school groups, there is a significant difference between the control group and the experimental group in terms of comprehensible input and vocabulary score, with $\mathrm{P}$ value being $0.000<0.05$, The experimental group (mean=9. 3750) outperforms the control group (mean=5. 4048 ) in both comprehensible input and vocabulary score. However, it is not the same case with the groups of the college school. It is found that there is no significant difference between the control group and the experimental group in terms of comprehensible input because the value of comprehensible input is constant (mean=5. 0000) and t-value can not be computed at all, whereas, a significant difference can be seen in vocabulary score between the control group and the experimental group $(\mathrm{P}=0.000<0.05)$. The experimental group $($ mean=3. 7143) outperforms the control group (mean=2. 1579).

Table 4. Correlation between frequency of negotiation of meaning, vocabulary score and comprehensible input in the high school groups

\begin{tabular}{lllll}
\hline & & Comprehensible input & Vocabulary score & Frequency of N/M \\
\hline \multirow{3}{*}{ Comprehensible input } & Pearson Correlation & 1 & $.313^{*}$ & $.310^{*}$ \\
& Sig. (2-tailed) & & .019 & .020 \\
& $\mathrm{~N}$ & 56 & 56 & 56 \\
& Pearson Correlation & $.313^{*}$ & 1 & $.761^{* *}$ \\
Vocabulary score & Sig. (2-tailed) & .019 & & .000 \\
& $\mathrm{~N}$ & 56 & 56 & 56 \\
\multirow{2}{*}{$\begin{array}{l}\text { Frequency of negation } \\
\text { meaning }\end{array}$} & Pearson Correlation & $.310^{*}$ & $.761^{* *}$ & 1 \\
& Sig. (2-tailed) & .020 & .000 & \\
\hline
\end{tabular}

In Table 4, it can be seen that there is a positive correlation between comprehensible input and frequency of negotiation of meaning $(\mathrm{P}=0.020<0.05)$ in the high school groups. It is also correlated with vocabulary score 
$(\mathrm{p}=0.019<0.05)$. In addition, vocabulary score and frequency of negotiation of meaning have a strong correlation with each other $(\mathrm{P}=0.000<0.05)$. It is worth mentioning that Pearson Correlation between vocabulary score and frequency of negotiation of meaning is much higher $(0.761)$ than other Pearson correlations $(0.313,0.310)$.

Table 5. Correlation between frequency of negotiation of meaning, vocabulary score and comprehensible input in the college experimental groups

\begin{tabular}{lllll}
\hline & & Frequency of N/M & Comprehensible input & Score \\
\hline \multirow{2}{*}{$\begin{array}{l}\text { Frequency of Negotiation } \\
\text { of meaning }\end{array}$} & Pearson Correlation & 1 & $*$ & .239 \\
& Sig. (2-tailed) & & $\cdot$ & .127 \\
& $\mathrm{~N}$ & 42 & 42 & 42 \\
& Pearson Correlation & $*$ & $*$ & $*$ \\
Comprehensible input & Sig. (2-tailed) &. & &. \\
& $\mathrm{N}$ & 42 & 42 & 42 \\
& Pearson Correlation & .239 & $*$ & 1 \\
Vocabulary score & Sig. (2-tailed) & .127 & $\cdot$ & \\
& $\mathrm{N}$ & 42 & 42 & 42 \\
\hline
\end{tabular}

* Cannot be computed because at least one of the variables is constant.

In Table 5, it is seen that different from the high school groups, no correlation can be found between frequency of negotiation of meaning and vocabulary score ( $\mathrm{P}=0.127>0.05)$ in the college groups. It is the same case with others. There is no correlation between frequency of negotiation of meaning and comprehensible input, vocabulary score because the value of comprehensible input is constant.

\subsection{Discussion}

1) When learning new words, can learners with negotiation of meaning acquire more comprehensible input than those without negotiation of meaning?

It is not simply noted that the participants in the experimental groups with negotiation of meaning could attain more comprehensible input than the control groups without negotiation of meaning. The situation in this experiment is more complicated than expected, which could be better illustrated in Table 3 and Table 4.

In the college groups, no correlation is found between frequency of negotiation of meaning and comprehensible input. That is to say, in the control group (pre-modified input plus non-negotiation of meaning), the participants attain the same level of comprehensible input as their counterparts in the experimental group (pre-modified input plus negotiation of meaning), which seems to support the results obtained by Ellis and He (1999), who find no significant difference in comprehensible input between the pre-modified input group and the interactionally modified input group. As far as the college students in this experiment are concerned, through the teacher's pre-modified input, the control group (pre-modified input + non-negotiation of meaning) also gets a good understanding of the target items. For instance:

Teacher: drastic means strong and violent.

Students: should be B.

Teacher: contraption means a strange - looking device

Students: should be C

Teacher: reiterate means restate, repeat, do or say something again and again

Students: should E

Teacher: drudge, do uninteresting and hard work.

Students: should be A. 
Teacher: contingent means accidental, by chance, by accident

Students: should be D. (See Match task 2)

With the assistance of teachers' explanations (pre-modified input), the participants in the control group get all the answers correct. It seems that pre-modified input could cause the same level of comprehension as pre-modified input plus negotiation of meaning. However, in the high school groups, a different report is made. A strong correlation is found between frequency of negotiation of meaning and comprehensible input. According to Table 4 , the correlation is significant at the 0.05 level $(0.02<0.05)$. In other words, the participants in the experimental group (negotiation of meaning and pre-modified input) obtain a higher level of comprehensible input than those in the control group (pre-modified input), which seems to support the previous studies made by Pica \& Doughty (1986), Pica, et al (1989), Loschky (1994), Fuente (2002) and Al-Mahrooqi \& Tuzlukova (2011), who claim that negotiation of meaning helps generate comprehensible input. According to Long (1985)'s interaction hypothesis, interaction provides comprehensible input. The more L2 interaction the learner holds with others, the more comprehensible input the learner will receive.

It is worth noting that taking a further look at Table 3 and Table 4, it is observed that the participants from the high school seem to rely more on negotiation of meaning than the college counterparts do with a view to attaining comprehensible input since no difference is found in comprehensible input between the experimental group and the control group from the college. By contrast, with the growth of age, the college participants might prefer to depend more on their cognitive ability instead of negotiation of meaning with peers or teachers. In other words, the college groups are able to comprehend the new words with pre-modified input without explicit ways of negotiation of meaning.

To summarize, in the high school experimental group (pre-modified input and negotiation of meaning), the participants are able to obtain more comprehensible input whereas the participants from the college experimental group (pre-modified and negotiation of meaning) attain merely the same level comprehensible input as those in the college control group (pre-modified input).

2) Is there a positive correlation between negotiation of meaning and L2 vocabulary acquisition?

To answer this question, two types of analyses are made, one is the independent samples T-test which intends to show whether or not there is any difference in vocabulary acquisition between the experimental groups and the control groups, and the other is correlation analysis that aims to investigate whether or not there is a positive correlation between frequency of negotiation of meaning and vocabulary acquisition. Both analyses support that vocabulary acquisition in this study has a positive correlation with negotiation of meaning except that the complicated findings in the college groups partly support the positive correlation.

Firstly, according to the independent samples T-test in Table 3, both of the experimental groups (mean=5. 8393, 3.7143 ,) outperform the two control groups (mean $=2.1667,3.7143$ ) in the post-vocabulary tests that are held a week later $(\mathrm{P}=0.000<0.05)$. The participants with the help of negotiation of meaning and pre-modified input do much better than those with only pre-modified input in acquiring new words.

Secondly, according to correlation analysis in Table 4 and Table 5, it is found that there is a positive correlation between frequency of negotiation of meaning and vocabulary acquisition in the high school groups. Pearson Correlation is $0.761, \mathrm{P}=0$. 000. It is believed that vocabulary acquisition of the high school participants is strongly affected by their frequency of negotiation of meaning with teachers or peers. Conversely, as regards the participants in the college groups, no correlation can be found between negotiation of meaning and vocabulary acquisition.

It is worth mentioning why the college experimental group (pre-modified input + negotiation of meaning) obviously outperforms the college control group (pre-modified input) in vocabulary acquisition, nevertheless, no strong correlation is found between frequency of negotiation of meaning and vocabulary acquisition in the college experimental group. It is partly because although there is no strong correlation between frequency of negotiation of meaning and vocabulary acquisition in the college experimental group, negotiation of meaning may provide a desirable situation in which the college experimental participants are able to make better use of their cognitive competence in acquiring new words so that eventually they can do better in vocabulary acquisition than the control group. It is also partly because the colleges participants may prefer to adopt implicit ways of negotiation of meaning that are not counted in this study.

To sum up, as far as the high school participants are concerned, negotiation of meaning with teachers or peers helps the participants to obtain more comprehensible input which promotes their vocabulary acquisition whereas as regards the college participants, negotiation of meaning with others makes no difference in their 
comprehensible input but finally facilitates their L2 vocabulary acquisition.

\section{Conclusion}

Based on the aforementioned results and analyses, the empirical study supports the effectiveness of negotiation of meaning in L2 vocabulary acquisition of Chinese learners of English. Firstly, in the high school groups, the experimental group (pre-modified input +negotiation of meaning) apparently outperforms the control group (pre-modified input) in terms of comprehensible input as well as vocabulary acquisition. The higher frequency of negotiation of meaning the participants have in the experimental group, the more comprehensible input they are able to obtain, and the better they perform in acquiring new words. Secondly, in the college groups, the experimental group (pre-modified input +negotiation of meaning) also outperforms the control group (pre-modified input) in terms of vocabulary acquisition. However, no difference is found between the experimental group and the control group in terms of comprehensible input, nor is a strong correlation found among comprehensible input, frequency of negotiation of meaning and vocabulary acquisition in the college experimental group. Finally, it seems that learners in the high school benefit more from negotiation of meaning and more rely on interaction with their teachers or peers when acquiring new words and obtaining comprehensible input whereas the college learners might prefer to depend on implicit ways of negotiation of meaning or cognitive competence in acquiring new words.

\section{References}

Al-Mahrooqi, R., \& Tuzlukova, V. (2011). Negotiating meaning in the EFL context. Pertanika J. Soc. SCI. \& Hum, 19(1), 183-196.

Bitchener, J. (2003). The value of negotiated interaction for learning vocabulary. The 16th educational conference Melbourne, Auckland University of technology.

Blake, R. (2000). Computer mediated communication: A window on L2 Spanish interlanguage. Language Learning and Technology, 4(1), 120-136.

Breen, M. (2002). Classroom decision making. Shanghai: Shanghai Foreign Language Education Press.

Ellis, R. (1985). Teacher-pupil interaction in second language development. In S. Gass, \& C. Madden (Eds.), Input in second language acquisition (pp. 69-85). Rowley, MA: Newbury House.

Ellis, R. (1995). Modified oral input and the acquisition of word meanings. Applied Linguistics, 16, 409-435.

Ellis, R. (1997). SLA research and language teaching. Oxford: Oxford University Press.

Ellis, R. (2003). Task-based language learning and teaching. New York: Oxford University Press.

Ellis, R. (2005). Analyzing learner language. Oxford: Oxford University Press.

Ellis, R., \& He. (1999). The roles of modified input and output in the incidental acquisition of word meanings. Studies in Second Language Acquisition, 21, 285-301.

Ellis, R., \& Heimbach, R. (1997). Bugs and birds: Children's acquisition of second language vocabulary through interaction. System, 25(2), 247-259.

Ellis, R., Tanaka, Y., \& Yamazaki, A. (1994). Classroom interaction, comprehension and the acquisition of second language word meanings. Language Learning, 44, 449-491.

Foster, P. (1998). A classroom perspective on negotiation of meaning. Applied Linguistics, 19(1), 1-23.

Foster, P., \& Ohta, A. S. (2005). Negotiation for meaning and peer assistance in second language classrooms. Applied Linguistics, 26, 402-430.

Fuente, M. (2002). Negotiation and oral acquisition of L2 vocabulary. SSLA, 24, 81-112.

Fuente, M. (2006). Classroom L2 vocabulary acquisition: Investigating the role of pedagogical tasks and form-focused instruction. Language Teaching Research, 10(3), 263-295.

Gass, S. M., \& Torres, M. J. A. (2005). Attention when? An investigation of the ordering effect of input and interaction. Studies in Second Language Acquisition, 27(1), 1-31.

Gass, S. M., \& Varonis, E. M. (1985). Task variation and nonnative/nonnative negotiation of meaning. In S. M. Gass, \& C. G. Madden (Eds.), Input in second language acquisition (pp. 149-161). Rowley, MA: Newbury House.

Gass, S. M., \& Varonis, E. M. (1994). Input, interaction, and second language production. Studies in Second Language Acquisition, 16, 283-302. 
Hardy, I. M., \& Moore, J. L. (2004). Foreign language students' conversational negotiations in different task environments. Applied Linguistics, 25(3), 340-370.

Jeong, Nam-Sook. (2011). Selected proceedings of the 2009 second language research forum. Luke Plonsky and Maren Schierloh (pp. 51-69).

Krashen, S. (1980). Second language acquisition and second language learning. Oxford: Pergamon Press.

Krashen, S. (1985). The input hypothesis: Issues and implications. London: Longman.

Lee, Byeong-Cheon. (2005). Negotiation of meaning and communication strategies in CMC. Sae Han English Language \& Literature, 47(1), 227-259.

Lee, Hyun-Gyung. (2006). Meaning negotiation in task-based video conferencing. Multimedia-Assisted Language Learning, 9(2), 128-153.

Long, M. H. (1981). Input, interaction, and second language acquisition. In H. Winitz (Ed.), Native Language and Foreign Language Acquisition: Annals of the New York Academy of Sciences (pp. 259-278). New York: New York Academy of Sciences.

Long, M. H. (1983). Linguistics and conversational adjustments to nonnative speakers. Studies in Second Language Acquisition, 4, 177-193.

Long, M. H. (1985). Input and Second language acquisition theory. In S. Gass, \& C. Madden (Eds), Input in second language acquisition (pp. 377-393). Rowly. MA: Newbury House.

Long, M. H. (1996). The role of the linguistic environment in second language acquisition. In W. C. Ritchie, \& T. K. Bhatia (Eds.), Handbook of second language acquisition (pp. 413-468). San Diego, CA: Academic Press.

Long, M. H. (2011). Instructed SLA (I): Towards a cognitive interactionist theory of instructed adult SLA. In workshop on second language research. Beijing: Beijing Foreign studies University.

Loschky, L. (1994). Comprehensible input and second language acquisition: What is the relationship? Studies in Second Language Acquisition, 16, 303-325.

Luan, N. L., \& Sappathy, S. M. (2011). L2 vocabulary acquisition: The impact of negotiated interaction. GEMA Online TM Journal of Language Studies, 5(11), 2.

Pica, T. (1987). Interlanguage adjustments as an outcome of NS-NNS negotiated interaction. Language Learning, $38,45-73$.

Pica, T. (1991). Classroom interaction, participation, and comprehension: Redefining relationships. System, 19, 437-452.

Pica, T. (1993). Choosing and using communication tasks for second language instruction. In G. Crookes, \& S. Gass (Eds.), Tasks and language learning: Integrating theory and practice (pp. 9-34). Bristol, PA: Multilingual Matters.

Pica, T. (1994). Research on negotiation: What does it reveal about second language learning conditions, processes, and outcome? Language learning, 44, 493-527.

Pica, T., \& Doughty, C. (1986). Making input comprehensible: Do interactional modifications help? ITL Review of Applied linguistics, 72, 1-25.

Pica, Teresa, Holiday, Lloyd, Lewis, Nora, \& Morgenthaler, Laura. (1989). Comprehensible output as an outcome of linguistic demands on the learner. Studies in Second Language Acquisition, 11, 63-90.

Révész, A., Sachs, R., \& Mackey, A. (2011). Task complexity, uptake of recasts, and second language development. In P. Robinson (Ed.), Researching task complexity: Task demands, task-based language learning and performance. John Benjamins.

Swain, M. (1985). Communicative competence: Some roles of comprehensible input and comprehensible output in its development. In S. M. Gass, \& C. G. Madden (Eds.), Input in second language acquisition (pp. 235-253). Rowley, MA: Newbury House.

Varonis, E. M., \& Gass, S. M. (1985). Non-native/non-native conversations: A model for negotiation of meaning. Applied Linguistics, 6(1), 71-90.

Yong, R. (1983). Negotiation of meaning in children's foreign language acquisition. ELT Journal, 37(3), 197-206.

Zhao, S. Y., \& Bitchener, J. (2007). Incidental focus on form in teacher-learner and learner-learner interactions. 
System, 35, 431-447.

\section{Appendix}

Test 1 A pre-vocabulary test for the high school participants

School: Class: Name: Sex: Date:

Translation:

1) Take after 2) Anxious 3) Strange 4) Favorite 5) Careful

6) I won't be long 7) Alien 8) Chase 9) Picnic 10) Develop

11) Pull down 12) Set up 13) Start 14) Make it clear 15) Drop

16) Hurt 17) Offer 18) Shy 19) Noise 20) Wind 21) Worried

22) Tie 23) Ocean 24) Cover 25) Used to 26) Separate

27) Downtown 28) Be terrified of 29) Block 30) Plenty

Test 2 A pre-vocabulary tests for the college participants

School: Class: Name: Sex: Date:

Translation

1) Bleat 2) Bite 3) Drudge 4) Assess 5) Sort 6) Astray

7) Astronaut 8) Contraption 9) Astonish 10) Assume

11) Enlarge

12) Enrage 13) Gorge 14) Reiterate 15) Superb 16) Drastic

17) Ability 18) Strike 19) Shock 20) Culture 21) Interaction

22) Regularly 23) Appointment 24) Vocabulary 25) Movable

26) Capable 27) Ritual 28) Enable 29) Mobile 30) Contingent

Match task 1

Class: Name: Sex: Date: Score:

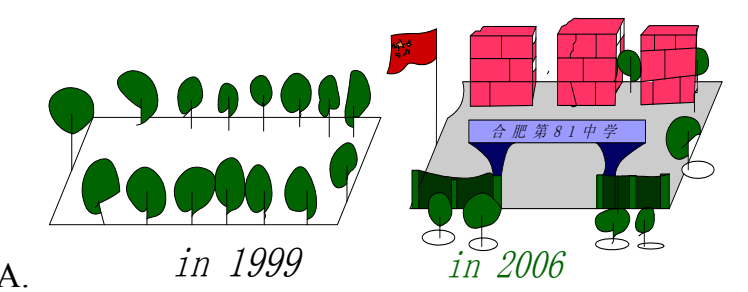

A.

B.

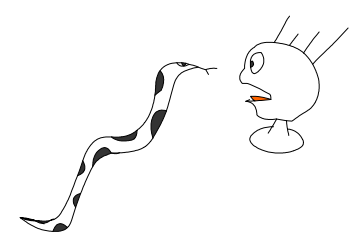

C.

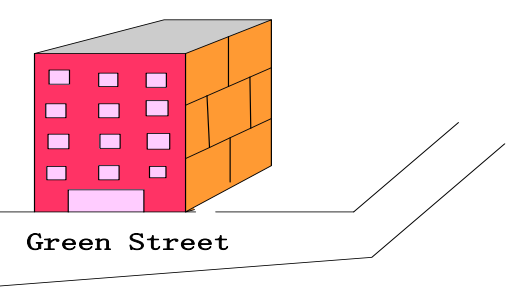

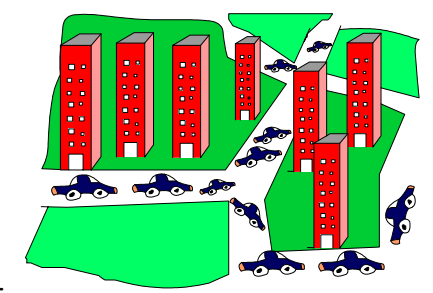

E.

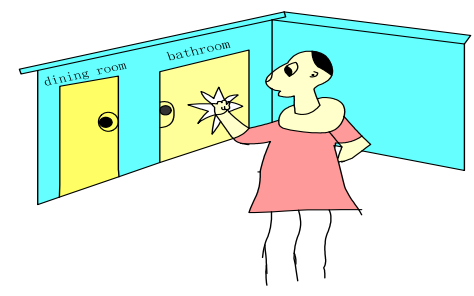


F.

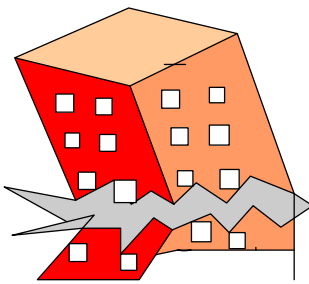

G.

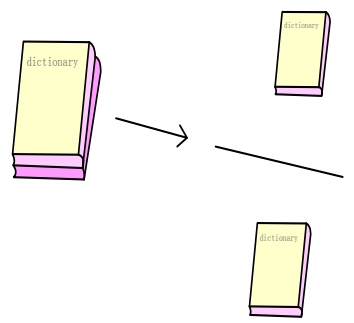

H.
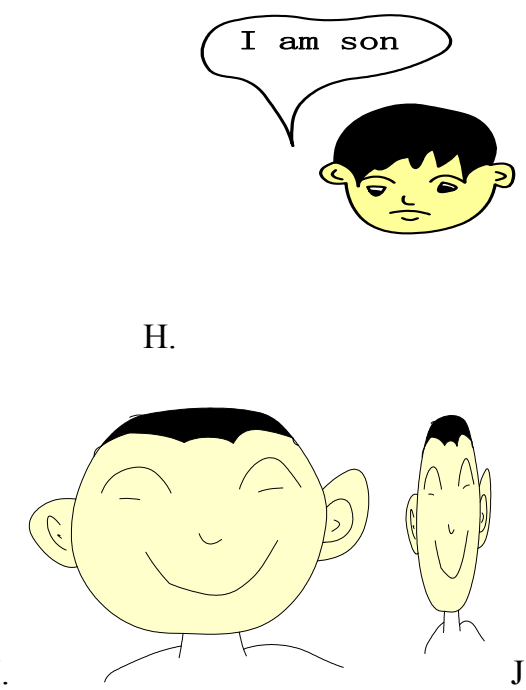

J.

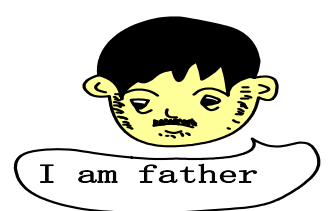

( ) 1 take after ( ) 2. I won't be long. ( ) 3. pull down. ( ) 4. set up ( )5.used to

( ) 6. separate ( ) 7. downtown ( ) 8.be terrified of ( ) 9.block ( )10. ocean.

Match task 2

Class: Name: Score: Sex: Date:
A. zuokugong
B.jilide C.qimiaodejixiezhangzhi
D.ourande
E. fanfudishuo

1. drastic:

2. contraption:

3. reiterate:

4. drudge :

5. contingent:

Test $3 \mathrm{~A}$ post-vocabulary test for the high school participants
Class:
Name:
Sex:
Date: Score:

Use the appropriate forms of the following words to fill in the blank:

Separate won't be long be terrified of downtown ocean used to

Block take after set up pull down

1. The old man decided to a school in his hometown

2. I guess Tom must be your son, because he you in all aspects.

3. My house is three far away from the school.

4. The whole house has been by the flood.

5. She be a teacher but now she is a nurse.

6. At night, Kate (Haipa) the ghost.

7. In the morning he went to (shizhongxin) 。

8. (haiyang) is bigger that a sea. 
9. - When will you come back? - I

10. No one can you from me.

Test 4 A post-vocabulary test for the college participants

Class: Name: Sex: Date: Score:

Use the appropriate forms of the following words to fill in the blank:

drudge, contraption, reiterate, contingent, drastic.

1. To pay his debt he had to at the work in a coal mine.

2. The police took measures to put a stop to the crime wave.

3. That's a curious , what is it for?

4. Such risks are to the trade.

5. Let me that we have absolutely no plans to increase taxation.

\section{Copyrights}

Copyright for this article is retained by the author(s), with first publication rights granted to the journal.

This is an open-access article distributed under the terms and conditions of the Creative Commons Attribution license (http://creativecommons.org/licenses/by/3.0/). 